\title{
On the Integration of Musical Elements Into the Teaching of the Research on the Theory and Practice of Socialism With Chinese Characteristics
}

\begin{abstract}
Yu Zhou, ${ }^{1, *}$
Shanghai Institute of Technology, Shanghai,201418, China

"fudzhy@163.com

ABSTRACT

With the development of education and the needs of the times, the number of graduate students in China is growing, and their mental health education is worthy of attention. The current methods are to strengthen the party construction and ideological and political education of graduate students, organize mass organizations, guide social practice, strengthen psychological guidance, strengthen incentive mechanism, solve students' life difficulties, etc. In response to this problem, the ideological and political theory teachers should actively take actions, reasonably use the music elements, effectively organize the case teaching of the ideological and political theory course for postgraduates, guide the students to identify with the mainstream ideology, shape the healthy personality of the true, the good and the beautiful, and hone the healthy and strong physique, which is an effective supplement to the above methods.
\end{abstract}

Keywords: graduate student, moral education, aesthetic education

\section{论音乐元素融入《中国特色社会主义理论与实践研究》

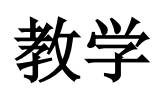

周妤 1 , a

\begin{abstract}
上海应用技术大学 上海 中国 201418
fudzhy@163.com
\end{abstract}

\begin{abstract}
摘要 壮的体格, 不失为上述方法的有效补充。

关键词: 研究生, 德育, 美育

\section{1. 前言}

研究生是一个由不同年龄、不同家庭背景、不同学 历背景构成的结构复杂的群体。“有直接从本科毕业后 读硕士再读博士的, 也有工作若干年以后再来攻读研究 生学位的。因此, 在校的部分硕士研究生和博士研究生 承受担着个人科研任务、家庭、就业等多方面的压力, 由于压力过大, 往往会产生一些心理问题, 甚至出现心 理疾病”。而教师探讨用音乐缓解心理压力之法, 进而探 索培养研究生的综合素质，具有必要性和可行性。
\end{abstract}

随着教育发展和时代需要, 中国研究生数量不断增长, 其心理健康教育值得关注。目前的办法有加强 研究生党建与思想政治教育、组织社团活动、引导社会实践、加强心理辅导、强化激励机制、解决学 生生活困难等。因应这个问题, 思想政治理论课教师要积极作为, 合理运用音乐元素, 有效地组织研 究生思想政治理论课的案例教学, 引导学生认同主流意识形态, 塑造真善美的健康人格, 磨研健康强

\section{2. 音乐节目信息归类}

《中国特色社会主义理论与实践研究》是硕士研究 生的思想政治理论必修课, 2018 年第一次以教材形式 编写出版。宋海儆认为该课程 “是一门比较新的硕士生 公共政治课，加强其课程建设是一个迫切的任务”。 加强音乐元素的案例教学会促进教学内容入脑入心，教 学方式灵活有效。汤玮琳认为: “思政教育与音乐欣赏 教育结合, 能够改变传统的以理论讲解为主的教育模式, 从而突出一种以欣赏、感悟、探究为主的新型的思政教 
育模式。”[3]

党的十八大以来, 中宣部主办、中央电视台承办了 一系列接地气、暖人心、独具匠心、引领文艺潮流的大 型精品节目播出, 传播了马克思主义中国化、时代化、 大众化的光辉历程, 宣传了习近平新时代中国特色社会 主义思想。教师可以选择合适的节目用于案例教学。这 些节目有: 中央电视台2015年11月29日播出的《共筑中 国梦—— “中国梦” 主题新创作歌曲演唱会》、2017 年11月29日播出的《同圆中国梦交响音乐会》、2018年 12 月 18 日庆祝改革开放 40 周年文艺晚会《我们的四十 年》、2019年9月30日播出的庆祝中华人民共和国成立 70 周年大型文艺晚会《奋斗吧 中华儿女》和《2019江山 如画国庆音乐会》、10月3日播出《中国歌剧光荣绽放》、 10 月 4 日播出的《中国歌曲大会国庆盛典》、10月5日播 出的《为人民歌唱一一中国乐派声乐大师郭兰英艺术成 就音乐会》等。

其中《奋斗吧中华儿女》是以音乐舞蹈史诗形式呈 现的庆祝中华人民共和国成立70周年文艺晚会, 由杨笑 阳担任总导演。该晚会以 “奋斗”为主线, 全要素运用 交响、合唱、舞蹈、朗诵、情景表演等手段, 再现一代 又一代中华儿女为民族独立、国家富强不解奋斗的伟大 历程。奋斗是该晚会的创作主题, 人民是表现主体, 主 创团队努力赋予《奋斗吧 中华儿女》新时代的艺术美, 调动各种舞台手段创新表达, 使其更符合观众的审美习 惯。该晚会既对标了《东方红》等经典, 也致敬了革命 前辈、艺术前辈, 从创作、制作到舞台呈现, 从词曲、 演唱、演奏、编排到服装、化妆、道具等各流程和门类 都要求很高。该晚会四个篇章的音乐从一大批歌曲中甄 选, 体量远远超过其他三部音乐舞蹈史诗。该晚会除了 增加演出场次、开展电视播出外, 还被拍成了一部艺术 电影, “这个电影是继《东方红》《复兴之路》等之后又 一部大型音乐舞蹈史诗的艺术电影, 希望通过电影艺术 的手段更加准确、全面、立体地再现好舞台演出的风采, 让舞台演出展现出更加恢弘的艺术美感和审美气质。”[4] 诚如《人民日报》记者评论: “伟大时代呼唤伟大创造, 崇高事业激发崇高感情。《奋斗吧 中华儿女》主创团队 以真诚的祝福献给祖国和人民, 以奋斗的精神向着艺术 高峰攀登。” ${ }^{[5]}$ (节目见表1)

表 1 《奋斗吧中华儿女》节目单

\begin{tabular}{|l|l|}
\hline 编章 & \multicolumn{1}{|c|}{ 节目 } \\
\hline & 《没有共产党就没有新中国》 \\
& 《起来 起来》《《国际歌》《工农兵联合起 \\
第 一 & 来》《南昌起义》《秋收起义歌》 \\
篇章 & 《西江月・井冈山》《三大纪律八项注 \\
浴 血 & 意》《娘子军连歌》《露营之歌》《过雪山 \\
奋斗 & 草地》《南泥湾》《延安颂》《怒吼吧 黄 \\
& $\begin{array}{l}\text { 河》《大刀进行曲》《弹起我心爱的土琵 } \\
\end{array}$ \\
& 琶》《渡江 渡江》《中国人民解放军进行 \\
\hline 第 二 & 曲》等 \\
\hline
\end{tabular}

\begin{tabular}{|c|c|}
\hline $\begin{array}{l}\text { 篇 章 } \\
\text { 艰 苦 } \\
\text { 奋斗 }\end{array}$ & $\begin{array}{l}\text { 《英雄赞歌》《我的祖国》《我们走在大 } \\
\text { 路上》《我为祖国献石油》《幸福不会从 } \\
\text { 天降》《接过雷锋的枪》共和国之恋》《歌 } \\
\text { 唱祖国》 等 }\end{array}$ \\
\hline $\begin{array}{l}\text { 第 三 } \\
\text { 篇 章 } \\
\text { 团 结 } \\
\text { 奋斗 }\end{array}$ & $\begin{array}{l}\text { 《祝酒歌》《在希望的田野上》《春天的 } \\
\text { 故事》《战决口》《东方之珠》 演唱: 解 } \\
\text { 晓东; 36. 《七子之歌》《故乡的云》《走 } \\
\text { 进新时代》《生死不离》《我和你》《江山》 } \\
\text { 《长江之歌》等 }\end{array}$ \\
\hline $\begin{array}{ll}\text { 第 } & \text { 四 } \\
\text { 篇 } & \text { 章 } \\
\text { 奋 } \text { 斗 } \\
\text { 吧 } \\
\text { 华 }\end{array}$ & $\begin{array}{l}\text { 《天耀中华》《致敬人民》《一个不能少》 } \\
\text { 《强军战歌》《《我的绿水青山》《赤子》 } \\
\text { 《新的天地》《不忘初心》《和平一一命 } \\
\text { 运共同体》《复兴的力量》《奋斗吧中华 } \\
\text { 儿女》等 }\end{array}$ \\
\hline
\end{tabular}

\section{3. 音乐节目对接教材分析}

音乐作品案例在该课程课堂教学的使用方法为: 整 套节目案例教学, 适合导论和结束语内容; 编章节目案 例教学、主题节目案例教学, 适合某个章节的开编或者 总结; 单个节目案例教学, 适合章节目某个知识点的对 应。（见表2）

表 2 中央电视台国庆期间播出的大型歌舞类节目对 接《中国特色社会主义理论与实践研究》内容参考表

\begin{tabular}{|c|c|c|}
\hline 教材内容 & 对应节目 & 案例教学目标 \\
\hline 导论 & $\begin{array}{l}\text { 《共筑中国梦》 } \\
\text { 《天耀中华》 } \\
\text { 《盛世欢歌》 } \\
\text { 《时代号子》等 }\end{array}$ & $\begin{array}{l}\text { 领会中国特色 } \\
\text { 社会主义的四 } \\
\text { 个自信 }\end{array}$ \\
\hline $\begin{array}{l}\text { 第一章 中国 } \\
\text { 特色社会主义 } \\
\text { 进入新时代 }\end{array}$ & $\begin{array}{l}\text { 《新的天地》 } \\
\text { 《奋进新时代》 } \\
\text { 《每个人都有 } \\
\text { 一个中国梦》等 }\end{array}$ & $\begin{array}{l}\text { 领会我国仍然 } \\
\text { 长期处于社会 } \\
\text { 主义初级阶段 } \\
\text { 的基本国情。 }\end{array}$ \\
\hline $\begin{array}{l}\text { 第二章 新时 } \\
\text { 代中国共产党 } \\
\text { 的历史使命 }\end{array}$ & $\begin{array}{l}\text { 《没有共产党 } \\
\text { 就没有新中国》 } \\
\text { 《东方红》《不 } \\
\text { 忘初心》等 }\end{array}$ & $\begin{array}{l}\text { 领会中国共产 } \\
\text { 党的初心和使 } \\
\text { 命。 }\end{array}$ \\
\hline $\begin{array}{l}\text { 第三章 中国 } \\
\text { 特色社会主义 } \\
\text { 经济建设 }\end{array}$ & $\begin{array}{l}\text { 《我的要求不 } \\
\text { 算高》《坐上高 } \\
\text { 铁去北京》《一 } \\
\text { 带一路畅想曲》 } \\
\text { 等 }\end{array}$ & $\begin{array}{l}\text { 领会改革开放 } \\
40 \text { 多年中国特 } \\
\text { 色社会主义建 } \\
\text { 设的伟大成 } \\
\text { 就。 }\end{array}$ \\
\hline $\begin{array}{l}\text { 第四章中国特 } \\
\text { 色社会主义的 } \\
\text { 政治建设 }\end{array}$ & $\begin{array}{l}\text { 《社会主义好》 } \\
\text { 《英雄赞歌》 } \\
\text { 《东方之珠》 } \\
\text { 《七子之歌》等 }\end{array}$ & $\begin{array}{l}\text { 领会人民当家 } \\
\text { 作主、坚持“一 } \\
\text { 国两制” 和祖 } \\
\text { 国统一的理 } \\
\text { 论。 }\end{array}$ \\
\hline
\end{tabular}




\begin{tabular}{|c|c|c|}
\hline $\begin{array}{l}\text { 第五章中国特 } \\
\text { 色社会主义文 } \\
\text { 化建设 }\end{array}$ & $\begin{array}{l}\text { 《摇篮曲》《春 } \\
\text { 节序曲》《孝和 } \\
\text { 中国》《好儿好 } \\
\text { 女好江山》等 }\end{array}$ & $\begin{array}{l}\text { 领会推动中华 } \\
\text { 优秀传统文化 } \\
\text { 创造性转化、 } \\
\text { 创新性发展。 }\end{array}$ \\
\hline $\begin{array}{l}\text { 第六章中国特 } \\
\text { 色社会主义社 } \\
\text { 会建设 }\end{array}$ & $\begin{array}{l}\text { 《时间都去哪 } \\
\text { 儿了》 《阳光》 } \\
\text { 《一个都不能 } \\
\text { 少》《脱贫宣言》 } \\
\text { 等 }\end{array}$ & $\begin{array}{l}\text { 领会增进民生 } \\
\text { 福祉、打赢脱 } \\
\text { 贫攻坚战、维 } \\
\text { 护社会和谐稳 } \\
\text { 定。 }\end{array}$ \\
\hline $\begin{array}{l}\text { 第七章中国特 } \\
\text { 色社会主义生 } \\
\text { 态文明建设 }\end{array}$ & $\begin{array}{l}\text { 《长江之歌》 } \\
\text { 《我的绿水青 } \\
\text { 山》《看山看水 } \\
\text { 看中国》等 }\end{array}$ & $\begin{array}{l}\text { 领会坚持人与 } \\
\text { 自然和谐共 } \\
\text { 存、新时代建 } \\
\text { 设美丽中国。 }\end{array}$ \\
\hline $\begin{array}{l}\text { 第八章 坚持 } \\
\text { 和平发展道路 } \\
\text { 与构建人类命 } \\
\text { 运共同体 }\end{array}$ & $\begin{array}{l}\text { 《让世界听见》 } \\
\text { 《我和我的祖 } \\
\text { 国》《和平一一 } \\
\text { 命运共同体》等 }\end{array}$ & $\begin{array}{l}\text { 领会构建人类 } \\
\text { 命运共同体的 } \\
\text { 含义和意义。 }\end{array}$ \\
\hline $\begin{array}{l}\text { 第九章 坚持 } \\
\text { 党对一切工作 } \\
\text { 的领导与全面 } \\
\text { 从严治党 }\end{array}$ & $\begin{array}{l}\text { 《把一切献给 } \\
\text { 党》《复兴的力 } \\
\text { 量》《强军战歌》 } \\
\text { 《光荣与梦想》 } \\
\text { 等 }\end{array}$ & $\begin{array}{l}\text { 领会中国共产 } \\
\text { 党来自于人 } \\
\text { 民、根植于人 } \\
\text { 民、服务于人 } \\
\text { 民。 }\end{array}$ \\
\hline
\end{tabular}

\section{4. 案例教学举例}

音乐作品案例在该课程研究性教学的使用方法为: 教师指导教学班级的学生分为 3-5 人的小组, 选择 1 首 音乐作品进行鉴赏, 写出文本, 作出 PPT 和视频, 进行 演讲和表演实践。探究性学习设计包括: 作品文本、创 作背景、演唱提示、作品鉴赏、探究学习、相关作品举 例与分析等。教师将探究性学习案例设计与表演情况, 给予判定成绩, 作为平时成绩的一个部分。以歌曲《我 们都是追梦人》“探究学习” 为例。

\section{1 创作背景}

2019 年春节前夕, 春晚导演组向王平久发出作品邀 约, 希望他为春晚创作一曲, 但他迟迟没有灵感。直到 他听到《2019 年新年贺词》中的 “我们都在努力奔跑, 我们都是追梦人”, 这句话触动了王平久。于是, 他把 《我们都是追梦人》作为歌名报给了春晚导演组。随后, 他找来常石否创作曲子。在创作过程中, 王平久和常石 否对该曲进行了策划, 同时要兼容年轻听众的传播, 于 是在创作方向上加入时尚化的元素。

\section{2 歌曲鉴赏}

《我们都是追梦人》中, 常石否的作曲很时尚, 充 满了新鲜元素, 让主流歌曲做到了老少皆宜。该曲的旋
律优美, 朗朗上口。伴着该曲欢快的旋律, 让听众在奔 跑中拥抱梦想, 感受作为一位追梦人的喜悦。该曲通过 秦岗、江疏影、景甜、TFBOYS、吴否的演绎，很好的诠 释出该曲青春洋溢的特质。

\section{3 对接教材}

教材的 “第二章新时代中国共产党的初心使命” 中 指出: “中国梦意味着中国人民和中华民族的价值认同 和价值追求, 意味着每一个中国人都能够在为中国梦的 奋斗中实现梦想。” ${ }^{[6]}$ 因此, 在中国特色社会主义进入新 时代之际，人们 “用歌曲讴歌中国梦、阐释中国梦、唱 响中国梦, 对于凝聚各方力量, 激励人们投身民族复兴, 实现中国梦的伟大事业具有重要意义”。[7]

\section{4 学习目的}

\section{4. 1 理解歌曲的传唱情况}

从 2014 年起, 《光明日报》报陆续刊登了由 “中 国梦” 主题歌曲创作推广组委会遴选出的《光荣与梦想》 《时间都去哪儿了》等 “中国梦” 主题新创作歌曲。《我 们都是追梦人》是该报开设《第七批 “中国梦” 主题新 创作歌曲》专栏中向读者推介新一批优秀歌曲之一。

歌曲《我们都是追梦人》是秦岗、江疏影、景甜、 TFBOYS、吴否共同演唱的歌曲, 收录于音乐专辑《2019 春晚歌曲抢先听》。2019 年, 该曲获得第 15 届精神文明 建设“五个一工程奖”优秀作品奖。2020 年 5 月 22 日, 荣获第九届北京市文学艺术奖。词作家王平久在接受北 京青年报记者采访时说: “这首歌唱出了时代的节奏, 因此深受广大观众的喜爱。” ${ }^{87}$ 因此, 该歌曲一经推出就 迅速地登上各大盛会舞台。尤其值得自豪的是, 歌曲还 作为冬奥倒计时 1000 天官方庆祝活动重要曲目表演。 与此同时, 歌曲先后推出了军营版、航空版、警察版、 大学生版、青少年版、广场舞版、手语版, 为宣传 “中 国梦”助力。

《我们都是追梦人》是一首具有时代意义的歌曲, 这 首歌呈现了当代中国人的奋斗方向, 歌词朝气蓬勃, 富 有精神感染力, 传唱方式也多种多样, 顺应了当代中国 的发展趋势, 深受国内外中国人的喜爱。歌曲《我们都 是追梦人》虽然是 2019 年刚出的新曲, 但因为他在歌 词和传唱上体现出当代中国人的奋斗方向和中国时代 精神, 所以这首歌将一直唱出我们中国人的共同梦想。

\subsection{2 挖掘歌曲的核心精神}

习近平认为: “中国梦是国家的、民族的，也是每 一个中国人的。国家好，民族好，大家才会好。” ${ }^{[9]}$ 《我 们都是追梦人》及时地表达了在新时代、新征程的大环 境下的主旋律, 歌颂了 “有梦想就有目标, 有希冀才会 
奋斗。无论国家、社会还是个人, 梦想都是保持生机、 激发活力的源泉” ${ }^{[10]}$ 的时代精神。

\section{5 问题提出 (发散思维)}

教师引导学生提出拓展性问题, 集思广益, 引发课题讨 论, 形成共识, 将探究性学习推向高潮。

\subsection{1 什么是中国梦? 中国梦的历史依据和发} 展脉络是什么?

用 “中国梦” 来概括中华民族伟大复兴，是因为中 国梦是一种形象的表述，是一种为群众易于接受的表述。 依据习近平多次讲话内容的表述: 中国梦的 “核心内涵 是中华民族伟大复兴”，“基本内涵是实现国家富强、 民族振兴、人民幸福” , “在新的历史时期, 中国梦的 本质是国家富强、民族振兴、人民幸福。”他强调: “中 国梦归根到底是人民的梦”，“中国共产党在中国执政， 就是要带领人民把国家建设得更好, 让人民生活得更 好”, “人民对美好生活的向往, 就是我们的奋斗目 标”。

我们要结合中华民族五千多年的文明发展历程特 别是近代以来一百六十多年的历史, 因为中国梦既是历 史的、现实的, 又是未来的。从 1840 年起, 中华民族 为实现中国梦, 整整走过了一个多世纪, 才迈出了赢得 民族独立、人民解放的第一步。在这一百余年的前 80 年间, 中国人民始终在黑暗中探索。只有中国共产党的 诞生和奋斗, 才把中国从黑暗引向了光明。在整个中国 革命中, 中国共产党为了实现 “中国梦” 牺牲了数百万 优秀党员, 中华民族牺牲了上千万英雄儿女, 英烈们的 鲜血染红了五星红旗。对于这段历史、对于为这段历史 而献身的先烈，中国人要永远铭记。

\section{5.2 同学们怎样在新时代为实现中华民族伟 大复兴的中国梦去奋斗?}

同学们在实现中国梦的追求中, 要牢记习近平的重 托, 既要有担当意识, 更要靠实干精神。值得欣慰的是: 我们比历史上任何时期都更接近实现中华民族伟大复 兴的目标, 比历史上任何时期都更有信心、更有能力实 现这个目标。作为新时代的青年学生, 一要刻苦学习各 种知识, 为实现中国梦准备过硬的业务本领; 二是要坚 定理想信念, 牢固地树立起正确的世界观、人生观和价 值观; 三是要学以致用, 注重调查研究, 在社会实践中 探索解决实际问题的本领, 将实现社会需要与自我价值 相结合。

\section{6 活动小结}

教师指导同学们结合当代中国的国内外局势，了解 《我们都是追梦人》的创作历程和社会背景, 参考歌曲 的传唱视频, 通过社会实践活动设计, 精心准备情景剧, 制作课件, 在课堂展示《我们都是追梦人》, 深刻理解 新时代青年秉持初心使命, 怀揣梦想, 扩大学生的受益 面, 引导学生树立正确的三观, 从课堂教学改革的角度 探索提高学生括思想品德、学业水平、身心健康、艺术 素养和社会实践 5 项综合素质。

\section{5. 结束语}

近年来艺术素质教育已成为美育教育的重要组成 部分, 同时艺术素质教育对于促进学生全面发展具有不 可代替的作用, 对于提高学生的思想道德素质、科学文 化素质、身心健康素质和劳动技能素质都具有深远意义。

据了解国家相关部门曾多次出台相关文件, 包括教 艺（2014）１号、教体艺（2015）５号、国办发 (2015) 71 号等文件。这些文件的出台, 意味着以往校园教育中 不被重视的艺术教育学科终于在国家政策层面得到了 肯定, 美育教育的重要意义再一次得到凸显和强调。

从学科融合发展来看, 思想政治教育与音乐教育协 同育人是一个可行而又迫切的课题。德育和美育的协调 发展, 必将对相关学科的创新发展提供新的机遇。

从人才培养的角度上看, 培养德智体美劳全面发展 的时代新人是每一位教育工作者的责任。2020 年全国教 育工作会议上，针对德智体美劳的 “五育”，教育部部 长提出, 新的一年要对准体育、美育、劳动教育发力推 动教体相融合、划出美育硬杜杜构建劳动教育责任链条。 因为中国特色社会主义事业是面向未来的事业, 需要一 代又一代有志青年勇敢地、自觉地担当起继往开来的历 史责任。青年兴则国家兴, 青年强则国家强。青年一代 有理想、有本领、有担当，国家就有前途，民族就有希 望。我们完全有理由相信，教育界同仁通过多方面的努 力, 调动一些优质资源为教学改革服务, 就一定会取得 进展。

\section{项目基金}

本文为 2019 年度上海市学校艺术科研重 点项目《音乐教育与思想政治教育协同育人研 究》(HJYS-2019-A02)。

\section{REFERENCES}

[1] Chen N.K., Zhou B. (2018) Research on the dilemma and Countermeasures of the construction of graduate ideological and political education team, Reform and Opening up,9:79. 
[2] Song H.L. (2019) Research on the construction of online course of" theoretical and practical research on socialism with Chinese characteristics "- based on the perspective of professional master training,", Think Tank Era, 28:283.

[3] Tang W.L.(2017) The necessity and strategy of the combination of Ideological and political education and music appreciation, Art review, 20:75.

[4] Liang Q.P., Chen Q.X.(2019) Li Qun: The National Day gala will be made into an art film.http://politics.people.com.cn/n1/2019/0829/c1001-313 25518.html

[5] Ren S.S., Wang Y., Yang X.M. (2019) Best wishes to the motherland and the people -- recording a large-scale music and dance epic, < fight for the Chinese people > the main creative team, People's daily, October 3, 2019.

[6] Compilation team of this book. (2018) Research on theory and practice of socialism with Chinese characteristics, Higher Education Press, Beijing, pp.51.

[7] Guo C. (2019) Wang Pingiu -The Author of the interview song "we are all dreamers", Guangming Daily, September 1, 2019.

[8] LunB. Tian W.T. (2019) "We are all dreamers" Sings the rhythm of the times, Beijing Youth Daily, September 20, 2019.

[9] Xi J.P. (2018) "Xi Jinping talks about governing the country", Foreign language press, Beijing, pp.49.

[10] People's daily, 1st edition, January 2, 2019. 